\title{
Preparation of a monoclonal antibody against the carcinoembryonic antigen, glypican-3
}

\author{
YONGDONG ZHANG ${ }^{1}$, DONGRI QIU ${ }^{1}$, RONGHUA LI ${ }^{1}$, YAWU LIU ${ }^{2}$, SHUAINAN SHI $^{3}$ and YULIANG WANG ${ }^{3}$ \\ ${ }^{1}$ Department of Stomatology, Tianjin First Central Hospital, Tianjin 300192, P.R. China; ${ }^{2}$ Department of Clinical Radiology, \\ Kuopio University Hospital, FIN-70210 Kuopio, Finland; ${ }^{3}$ Department of Clinical Laboratory Medicine, \\ The Second Hospital of Tianjin Medical University, Tianjin Institute of Urology, Tianjin 300211, P.R. China
}

Received May 16, 2018; Accepted January 17, 2019

DOI: $10.3892 / \mathrm{mmr} .2019 .10019$

\begin{abstract}
The carcinoembryonic antigen, glypican-3 (GPC3), is a putative therapeutic target and diagnostic marker of hepatoma. In the present study, a monoclonal antibody (mAb) specifically against GPC3 was obtained via cloning the sequence of GPC3 via polymerase chain reaction and inserting it into a pET16b vector prior to transfection into Escherichia coli (E. coli) BL21. BALB/c mice were immunized with $20 \mu \mathrm{g}$ purified antigen by intrasplenic embedding. Splenocytes and mouse myeloma cells SP2/0 were fused; then, the hybridoma cells were screened by an indirect ELISA. The properties of the mAb were examined by western blotting and immunofluorescence analysis against the purified protein. The results revealed that the prokaryotic expression vector of GPC3 had been successfully generated and GPC3 was stably expressed in E. coli BL21. A stable hybridoma cell line, $2 \mathrm{~F} 3$, was generated in the present study, which produced mAbs against GPC3. The mAb 2F3 had a high antibody titer and the isotype was identified as $\mathrm{IgG} 1 / \kappa ; 2 \mathrm{~F} 3$ hybridomas had a median chromosome number of 98 . Western blot and immunofluorescence analyses revealed that $2 \mathrm{~F} 3$ specifically recognized recombinant and native GPC 3 . The $2 \mathrm{~F} 3$ clone was proposed as a stable secretor of this $\mathrm{mAb}$ against GPC3. The results of present study indicated that the successful preparation of recombinant GPC3 protein and an anti-human GPC3 mouse $\mathrm{mAb}$ may be provide a basis for developments in the diagnosis and treatment of liver cancer.
\end{abstract}

Correspondence to: Professor Yuliang Wang, Department of Clinical Laboratory Medicine, The Second Hospital of Tianjin Medical University, Tianjin Institute of Urology, 23 Pingjiang Road, Hexi, Tianjin 300211, P.R. China

E-mail: wang_yu_1@163.com

Key words: glypican-3, antigen purification, embedding immunology, monoclonal antibody, liver cancer

\section{Introduction}

Hepatoma, the most prevalent form of liver cancer, is the fifth most common malignant tumor, as well as the third leading cause of tumor-associated mortality worldwide (1); annually, $\sim 500,000$ new cases of hepatoma are diagnosed (2). China has the highest incidence of hepatoma and accounts for the majority $(55 \%)$ of all newly diagnosed liver cancer cases globally $(3,4)$. Novel diagnostic and therapeutic strategies are urgently required (5).

Glypican-3 (GPC3/OCI-5) is a $70 \mathrm{kDa}$ protein comprising 580 amino acids. It is a heparan sulfate proteoglycan that is anchored on the cell surface via glycosylphosphatidylinositol (6). GPC3 promotes the growth of hepatoma cells by stimulating the canonical Wnt signaling pathway (7). The expression, properties and regulation of carcinoembryonic antigen GPC3 have been examined; the protein is overexpressed in hepatoma tissues and the degree of the overexpression correlates with the poor prognosis of patients (8-10). Therefore, in the future, GPC3 may not only serve as a potential diagnostic biomarker, but also as an immunotherapeutic target against hepatoma.

The expression of antibodies against GPC3 may serve as a potential therapeutic strategy against hepatoma Therefore, a GPC3 prokaryotic expression vector was developed for the ectopic expression of GPC3 in Escherichia coli (E. coli) in the present study. Then, the purified GPC3 recombinant protein was used to immunize BALB/c mice via intrasplenic embedding, and subsequently a monoclonal antibody (mAb) was obtained and characterized.

\section{Materials and methods}

Experimental animals and cell lines. The present study was approved by the Institutional Animal Care and Use Committee of Tianjin First Central Hospital (Tianjin, China) and conformed to the Guide for the Use and Care of Animals published by the National Institutes of Health (NIH Publication number 85-23, revised 1996) (11). In total, eight female BALB/c mice (age, 8 weeks; weight, 18-20 g) were obtained from the Academy of Military Medical Science [Beijing, China; certificate no. SCXK (JUN) 2007-004]. Mice were housed at a temperature of $22-24^{\circ} \mathrm{C}$, relative humidity 
of $45-60 \%$, a 12-h light/dark cycle, with free access to food and water. Mouse myeloma cells (Sp2/0) and a human hepatoblastoma cell line (HepG2) were obtained from the Cell Bank of Shanghai Institute of Cell Biology (Chinese Academy of Medical Sciences, Shanghai, China). Hepatoblastoma is a rare disease; however, it is the most common type of primary hepatic malignancy encountered in infants and young children (12). SP2/0 cells were cultured in RPMI-1640 medium (Gibco; Thermo Fisher Scientific, Inc., Waltham, MA, USA) supplemented with $20 \%$ fetal bovine serum (FBS; Gibco; Thermo Fisher Scientific, Inc.). HepG2 cells were cultured in Dulbecco's Modified Eagle's medium (DMEM; Gibco; Thermo Fisher Scientific, Inc.) supplemented with 20\% FBS. The cells were incubated at $37^{\circ} \mathrm{C}$ in a humidified atmosphere containing $5 \% \mathrm{CO}_{2}$.

Clone of GPC3 gene. The template for GPC3 was created in accordance with the sequence from GenBank (accession no. NM_001164617; https:/www.ncbi.nlm.nih.gov/genbank/); the primer sequences for amplification of the GPC3 gene were as follows: Forward, 5'-ACGGGATCCGCCAAGAACTAC ACCAATGC-3' with the BamHI restriction site underlined; and reverse, 5'-ATTCTCGAGTTACTCCACCACACCTGC CATACA-3' with the XhoI restriction site underlined (Sangon Biotech Co., Ltd., Shanghai, China). The sequence was inserted into pDNOR223-GPC3 (IMMUSOFT, Seattle, WA, USA). The primers were synthesized by Takara Bio, Inc. (Tokyo, Japan). The polymerase chain reaction (PCR) amplification conditions were the following: In total, 30 cycles of $98^{\circ} \mathrm{C}$ for $10 \mathrm{sec}$, followed by annealing at $55^{\circ} \mathrm{C}$ for $15 \mathrm{sec}$, extension at $72^{\circ} \mathrm{C}$ for $30 \mathrm{sec}$ using an ABI 7500 Sequence Detection System (Applied Biosystems; Thermo Fisher Scientific, Inc.). The PCR product was analyzed by electrophoresis on a $1.0 \%$ agarose gel. Following staining with ethidium bromide solution $(10 \mathrm{mg} / \mathrm{ml}$; Sigma-Aldrich; Merck KGaA, Darmstadt, Germany), gel images were obtained.

Expression and purification of fusion protein. PCR fragments were digested using $B a m \mathrm{HI}$ and $X h o I$ restriction enzymes (10 U/ $\mu \mathrm{l}$; Takara Bio, Inc.) for $1 \mathrm{~h}$ at $37^{\circ} \mathrm{C}$ and then cloned into the BamHI- and XhoI-digested pET16b vector ecoding a His-tag (Novagen; Merck KGaA); successful cloning was confirmed by sequencing (Sangon Biotech Co., Ltd.). The recombinant plasmid was transfected into E. coli BL21 (DE3, Novagen; Merck KGaA) with the soluble fusion protein GPC3 expressed following induction with $0.1 \mathrm{mM}$ isopropyl- $\beta-\mathrm{D}$ thiogalactopyranoside (IPTG; Takara Bio, Inc.), and non-IPTG cells were used as control. The cultures were induced for $4 \mathrm{~h}$ at $37^{\circ} \mathrm{C}$. Affinity chromatography was used to purify the expressed fusion protein via a His-tag. The target fusion protein was expressed in inclusion body; thus, the bacterial cells were lysed using $4 \mathrm{ml}$ lysis buffer containing $50 \mathrm{mM}$ Tris-Hcl (pH 8.0), $300 \mathrm{mM} \mathrm{NaCl}$ and $8 \mathrm{M}$ urea. Lysed cells were subsequently mixed with $1 \mathrm{ml}$ of a solution provided in the kit containing the Nickel chelating resin (GE Healthcare, Chicago, IL, USA). The binding buffer contained $50 \mathrm{mmol} / 1$ $\mathrm{Na}_{2} \mathrm{HPO}_{4}, 300 \mathrm{mM} \mathrm{NaCl}, 6 \mathrm{M}$ guanidine at $\mathrm{pH}$ 6.0-8.0 and was used as the mobile phase at a flow rate of $\sim 1 \mathrm{ml} / \mathrm{min}$ at $4^{\circ} \mathrm{C}$. The protein was eluted using the elution buffer containing $50 \mathrm{mmol} / 1 \mathrm{Na}_{2} \mathrm{HPO}_{4}, 300 \mathrm{mM} \mathrm{NaCl}$ and $250 \mathrm{mM}$ imidazole at $\mathrm{pH}$ 8.0. The identity of the purified fusion protein was confirmed by SDS-PAGE and western blot analysis (13). The primary antibody used was rabbit anti-His-tag antibody (cat. no. ABIN398410; 1:5,000; antibodies-online GmbH, Aachen, Germany), and the secondary antibody was goat anti-rabbit immunoglobulin $\mathrm{G}$ ( $\mathrm{IgG})$-horseradish peroxidase antibody (cat. no. ABIN398323; 1:10,000; antibodies-online $\mathrm{GmbH}$ ). The concentration of the purified protein was determined using a Bradford protein assay kit (Beyotime Institute of Biotechnology, Shanghai, China).

Immunization of mice and preparation of hybridoma. Recombinant GPC3 protein ( $20 \mu \mathrm{g})$ was deposited onto nitrocellulose (NC) membranes (Sigma-Aldrich; Merck KGaA) in a drop-wise manner using a micro-syringe (Hamilton Bonaduz AG, Bonaduz, Switzerland). BALB/c mice were anesthetized with via isoflurane inhalation (1.0-2.0\%, induction; 2.0-2.5\% maintenance; Lunan Pharmaceutical Co., Ltd., Linyi, China) usinga VMR Small Animal Anesthesia Machine System (Midmark Corporation, Orchard Park, NY, USA). An NC membrane was embedded into the spleen via a $1-\mathrm{cm}$ surgical incision on the left side and the embedding procedure was repeated 2 weeks later. On day 21 following immunization, blood samples were obtained from the tail vein of mice. The serum was collected by centrifugation at 6,000 $\mathrm{x} \mathrm{g}$ and $4^{\circ} \mathrm{C}$ for $20 \mathrm{~min}$. An indirect ELISA was applied to assay serum antibody titers against GPC3 (13). The fusion protein $(10 \mu \mathrm{g} / \mathrm{ml})$ was used to coat microtiter plates, plates were incubated with dilutions of mice immunized serum. Subsequently, goat anti-mouse IgG-horseradish peroxidase (cat. no. sc-2005; 1:2,000; Santa Cruz Biotechnology, Inc., Dallas, TX, USA) was added. The final injection was administered intraperitoneally with $100 \mu \mathrm{g}$ of fusion protein antigen purified following chromatography and after 3 days, mice were sacrificed prior to harvesting of the spleens. Splenocytes from the immunized mice were collected and subsequently fused with pre-prepared SP2/0 cells with the standard methodology (14). In brief, the cells were washed twice with RPMI-1640 medium and pre-warmed 50\% polyethylene glycol 4000 (Sigma-Aldrich; Merck $\mathrm{KGaA}$ ), and then added to the cell pellet slowly with continuous agitation. Hypoxanthine-aminopterin-thymidine selection media (Sigma-Aldrich; Merck KGaA) was used to select for fused cells under $37^{\circ} \mathrm{C}$ in a humidified environment with $5 \% \mathrm{CO}_{2}$. The non-fused dead cells were removed by replacing the medium. The fused cells were seeded with RPMI-1640 medium into 96-well plates; the hybridoma culture supernatants were then initially screened by an indirect ELISA (15). Positive hybridomas, which secreted antibodies against the recombinant GPC3 protein, were cloned at least four times by a limiting dilution assay in Hypoxanthine-thymidine selection media at $37^{\circ} \mathrm{C}$ in a humidified environment with $5 \%$ $\mathrm{CO}_{2}$. Single positive hybridoma clones were expanded 4 days at $37^{\circ} \mathrm{C}$ in $75-\mathrm{cm}^{2}$ culture flasks and cryopreserved in liquid nitrogen [Air Products and Chemicals (Tianjin) Co., Ltd., Tianjin, China].

Production of mAbs. Selected positive clones of $5 \times 10^{6}$ hybridoma cells were injected into the peritoneum of three sterile female BALB/c mice (age, 8 weeks; weight, 18-20 g) (The Academy of Military Medical Science) primed with 
pristane (cat. no. P2870; Sigma-Aldrich; Merck KGaA). Mice were housed at a temperature of $22-24^{\circ} \mathrm{C}$, relative humidity of $45-60 \%$, with a 12 -h light/dark cycle. After 10 days, ascitic fluid $(3-5 \mathrm{ml})$ was first drained from the peritoneum for when the body weight of mice increased to 20-30\%; ascites collection was conducted for a total of three times. Multiple harvests were conducted two days apart; the second and third harvests were performed two days apart. Providing mice manifested signs of pain or were due for final ascites harvest, mice were euthanized by cervical dislocation prior to ascites collection. Subsequently, mAbs against GPC3 were purified using G-Sepharose 4B (Sigma-Aldrich; Merck KGaA), the affinity purification column (size, $5 \times 0.7 \mathrm{~cm}$ ) was filled with a sepharose cross-linked with protein $\mathrm{G}$. In total, $10 \mathrm{ml}$ ascitic fluid sample was clarified using centrifugation at a speed of $10,000 \times \mathrm{g}$ for $10 \mathrm{~min}$ at $4^{\circ} \mathrm{C}$ prior to column-based purification. The supernatant at $\mathrm{pH} 7.0$ was loaded through the protein G-agarose column at a flow rate of $1 \mathrm{ml} / \mathrm{min}$ at $4^{\circ} \mathrm{C}$ following by washing the column using 5 volumes of washing buffer containg $20 \mathrm{mmol} / 1 \mathrm{Na}_{2} \mathrm{HPO}_{4}, 150 \mathrm{mmol} / \mathrm{l} \mathrm{NaCl}$ and $2 \mathrm{mmol} / \mathrm{l}$ EDTA at pH 7.0 at the same flow rate and temperature. The antibodies were eluted using the elution buffer containing $100 \mathrm{mM}$ glycine at $\mathrm{pH}$ 2.7. The immunoglobulin-containing fraction was identified by measuring its absorbance at $280 \mathrm{~nm}$.

$m A b$ analysis. The mAb isotypes were determined using a mouse mAb isotyping kit (cat. no. 501240; Santa Cruz Biotechnology, Inc.) according to the manufacturer's protocols.

Chromosome counting of the hybridomas. The chromosome number of the hybridomas was determined in accordance with the International System for Chromosome Nomenclature 2013 (16). Cell division was inhibited in metaphase by adding $200 \mu \mathrm{g} / \mathrm{ml}$ colcemid (Invitrogen; Thermo Fisher Scientific, Inc.) at $37^{\circ} \mathrm{C}$ for $18 \mathrm{~h}$. The chromosome number was then assessed using an Ni-U fluorescence microscope (Nikon Corporation, Tokyo, Japan; magnification, 100x).

Western blot analysis. For western blotting, HepG2 cells were collected and lysed in radioimmunoprecipitation assay lysis buffer (Thermo Fisher Scientific, Inc.). In total, $50 \mu \mathrm{g}$ protein was loaded in each lane of the separation gel following protein concentration determination (Bradford's assay). Proteins were separated by $12 \%$ SDS-PAGE and electrophoretically transferred onto polyvinylidene difluoride membranes (Merck KGaA) with Mini PROTEAN (Bio-Rad Laboratories, Inc., Hercules, CA). Following three washes with Tris-buffered saline with $0.1 \%$ Tween 20 , the membrane was incubated with purified $\mathrm{mAb}(1: 1,000)$ at $37^{\circ} \mathrm{C}$ for $2 \mathrm{~h}$. Followed by washing as aforementioned, then goat anti-mouse IgG-horseradish peroxidase (cat no. sc-2005; 1:5,000; Santa Cruz Biotechnology, Inc.) was used as a secondary antibody and incubated at room temperature for $1 \mathrm{~h}$. The membranes were washed again and blots were visualized using enhanced chemiluminescence reagents (Thermo Fisher Scientific, Inc.). All experiments were repeated three times.

Immunofluorescence. HepG2 cells were plated onto a glass slide and cultured overnight at $4^{\circ} \mathrm{C}$; following washing with PBS, cells were fixed with ice-cold $4 \%$ paraformaldehyde for
$1 \mathrm{~h}$ and were blocked with bovine serum albumin (Beyotime Institute of Biotechnology) for $1 \mathrm{~h}$ at $37^{\circ} \mathrm{C}$. Following three washes with PBS, cells were incubated with $\mathrm{mAb}$ in a humidified chamber overnight at $4^{\circ} \mathrm{C}$ followed by washing as aforementioned. A fluorescent-labeled goat anti-mouse IgG (cat. no. sc-2010; 1:5,000; Santa Cruz Biotechnology, Inc.) was applied as the secondary antibody and cells were incubated at room temperature for $1 \mathrm{~h}$. Immunofluorescence was analyzed in 10 randomly selected fields of view using a Ni-U fluorescence microscope (magnification, x400).

\section{Results}

Construction of the prokaryotic expression vector. The PCR product ( $\sim 510 \mathrm{bp}$ ) was analyzed by $1 \%$ agarose electrophoresis (Fig. 1). Subsequently, the recombinant plasmid was digested by incubation with two restriction endonucleases, Bam HI and $X h o I$. Gel electrophoresis revealed that the cleavage of BamHI and $\mathrm{XhoI}$ had generated the target fragment, which was determined to have the expected size of 500 bp (Fig. 2). The fragment obtained from endonuclease cleavage was verified by sequencing (data not shown); the results were consistent with the sequence of GPC3 (Genbank, accession no. NM_001164617). These findings indicated the successful construction of the expression vector.

Expression, purification and identification of recombinant GPC3 protein. The plasmid pET16b-GPC3 was transfected into E. coli BL21 (DE3). Protein expression was induced by adding IPTG; a dense protein band with a molecular weight of $\sim 19 \mathrm{kDa}$ was detected in IPTG-induced cells (Fig. 3A). The location of the band corresponded to the theoretical molecular weight calculated for the recombinant GPC3 protein. Purification of the recombinant GPC3 protein by affinity chromatography via a His-tag was conducted with a purity of $\leq 95 \%$. Following purification, there appeared to be only one clear protein band with a molecular weight of $\sim 19 \mathrm{kDa}$ (Fig. 3B). This result was further confirmed by western blotting (Fig. 3C).

Production of specific hybridomas. Following immunization, splenocytes were fused with $\mathrm{Sp} 2 / 0$ to establish hybridomas; these were cultured in 96-well culture microtitration plates. Hybridoma cells secreting antibodies were screened by an indirect ELISA and sub-cloned three times in order to guarantee the monoclonal behavior of the IgGs. Finally, we obtained three positive hybridoma cell clones against recombinant GPC3 following cell fusion and sub-cloning.

Identification of the mAbs against GPC3. A stable hybridoma clone designated as $2 \mathrm{~F} 3$ and the corresponding antibody titers were determined to be $1: 10^{5}$ in ascites. Furthermore, $2 \mathrm{~F} 3$ was identified as being an $\mathrm{IgG} 1 / \kappa$ isotype. In addition, the median chromosome number of 2F3 was 98 (Fig. 4).

Western blot analysis. Western blot analysis demonstrated that $\mathrm{mAb} 2 \mathrm{~F} 3$ yielded a positive signal with the total cell extracts of HepG2 cells at a molecular weight of $\sim 70 \mathrm{kDa}$ (Fig. 5).

Immunofluorescence analysis of the specific $m A b$ against $G P C 3$. HepG2 cells were observed via fluorescence 


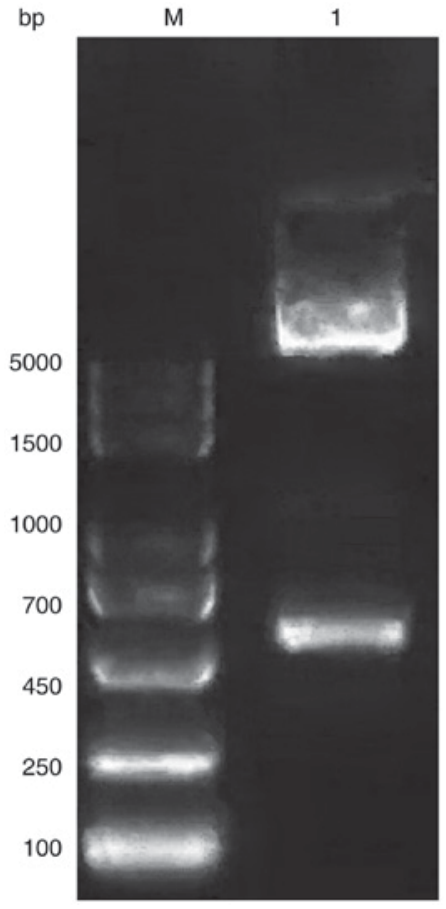

Figure 1. Agarose gel electrophoresis of PCR product. M, DNA marker; Lane 1, PCR product. PCR, polymerase chain reaction.

microscopy following staining with $\mathrm{mAb} 2 \mathrm{~F} 3$ (Fig. 6). The results indicated that $\mathrm{mAb} 2 \mathrm{~F} 3$ could react specifically with the native GPC3 protein in liver carcinoma cells.

\section{Discussion}

A confident diagnosis of cancer is a critical step prior to administrating any treatment. The targeting of cancer cell-specific proteins could result in more effective cancer treatments with fewer side effects. Thus, developments in reliable tumor markers, and the detection of antibodies or technologies are urgently required. For example, Ramucirumab, a fully humanized monoclonal antibody, was demonstrated to exhibit clinical efficacy and a favorable safety profile in the treatment of a number of malignancies including advanced liver cancer (17). GPC3 protein is distributed in the cytoplasm and present in the membranes of hepatocytes in cancerous tissues $(18,19)$; GPC3 has been considered as a promising biomarker for hepatoma-targeted therapeutics (20). In the present study, a fusion GPC3 protein was obtained from a prokaryotic expression system and an anti-human GPC3 mouse mAb was generated that specifically bound GPC3 protein in liver carcinoma cells.

In 1988, Filmus et al (21) isolated a developmentally-regulated cDNA clone, which was denoted as OCI-5, from a rat small intestine cell line. As the OCI-5 gene encodes a protein with extensive homology to the glypican family, the human gene was renamed as GPC3 (22). OCI-5 was determined to be located in the Xq26 region of the human chromosome, being bound onto the cell surface via a glycosylphosphatidylinositol anchor. There are six members of the glypican family (GPC1-6) (22). GPC3 is abundantly expressed in the placenta and numerous fetal tissues, including the liver, lung and kidney; however, GPC3 is significantly downregulated in the organs of adults (23). The GPC 3 gene encodes a core protein of 580

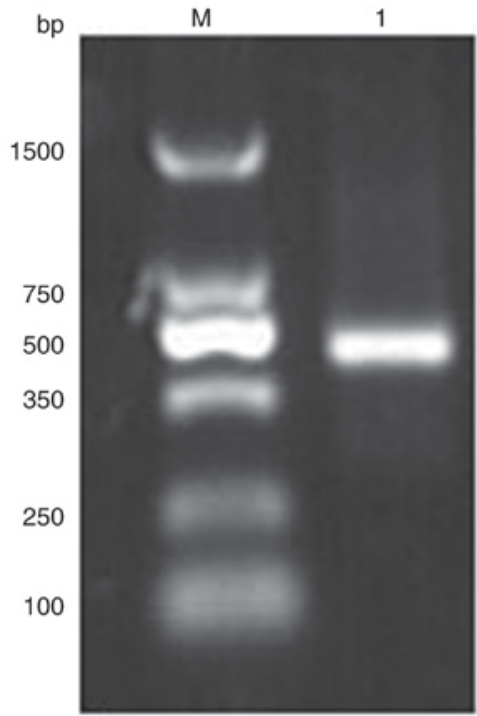

Figure 2. Gel electrophoresis of recombinant plasmid following BamHI and XhoI double enzymatic digestion.

amino acids with a mass of $70 \mathrm{kDa}$. GPC 3 can be released from the cell surface into the extracellular milieu (6). Accumulating evidence has indicated that GPC3 overexpression is closely associated with the malignant transformation of hepatocytes; GPC3 has been reported as a potential pathological diagnostic marker present in the serum of patients with hepatoma (24). In addition, GPC 3 is known to be a carcinoembryonic antigen with an involvement in cell proliferation and metastasis by stimulating Wnt signaling. Significant GPC3 expression in hepatoma tissues is a putative prognostic factor predicting the poor outcome of patients with hepatoma (10). Thus, humanized anti-GPC $3 \mathrm{mAb}$ may possesses notable cytotoxicity against GPC3-expressing human hepatoma cell lines in vivo; these effects may be mediated via antigen-dependent and/or complement-dependent cell cytotoxicity (25-27). Preliminary studies and clinical trials targeting GPC 3 via humanized anti-GPC3 mAb in hepatoma have been conducted (28-31).

In addition, the recombinant proteins produced in prokaryotic expression systems are immunogens for the preparation of mAbs or polyclonal antibodies. The E. coli system offers numerous advantages for protein expression, including low cost, convenience and good fermentation potential (32). In the present study, the GPC3 recombinant protein was expressed in E. coli BL21 and the purified protein was used to immunize $\mathrm{BALB} / \mathrm{c}$ mice in the generation of $\mathrm{mAbs}$. The results of SDS-PAGE demonstrated that the human GPC3 recombinant protein was obtained with a high degree of purity.

Hybridoma technology for $\mathrm{mAb}$ production has become well-established during the past decades (33). Certain mAbs against GPC3 have been produced and are commercially available; however, the method and process of mAb preparation described in the present study varied from traditional methods. $\mathrm{BALB} / \mathrm{c}$ mice were immunized with purified antigen via intrasplenic embedding. Furthermore, antibodies that recognize a conformational epitope could be easily obtained from mice immunized via intrasplenic embedding. Thus, we have successfully demonstrated a rapid, easy, feasible and reliable method to prepare $\mathrm{mAbs}$ by expressing recombinant protein following 

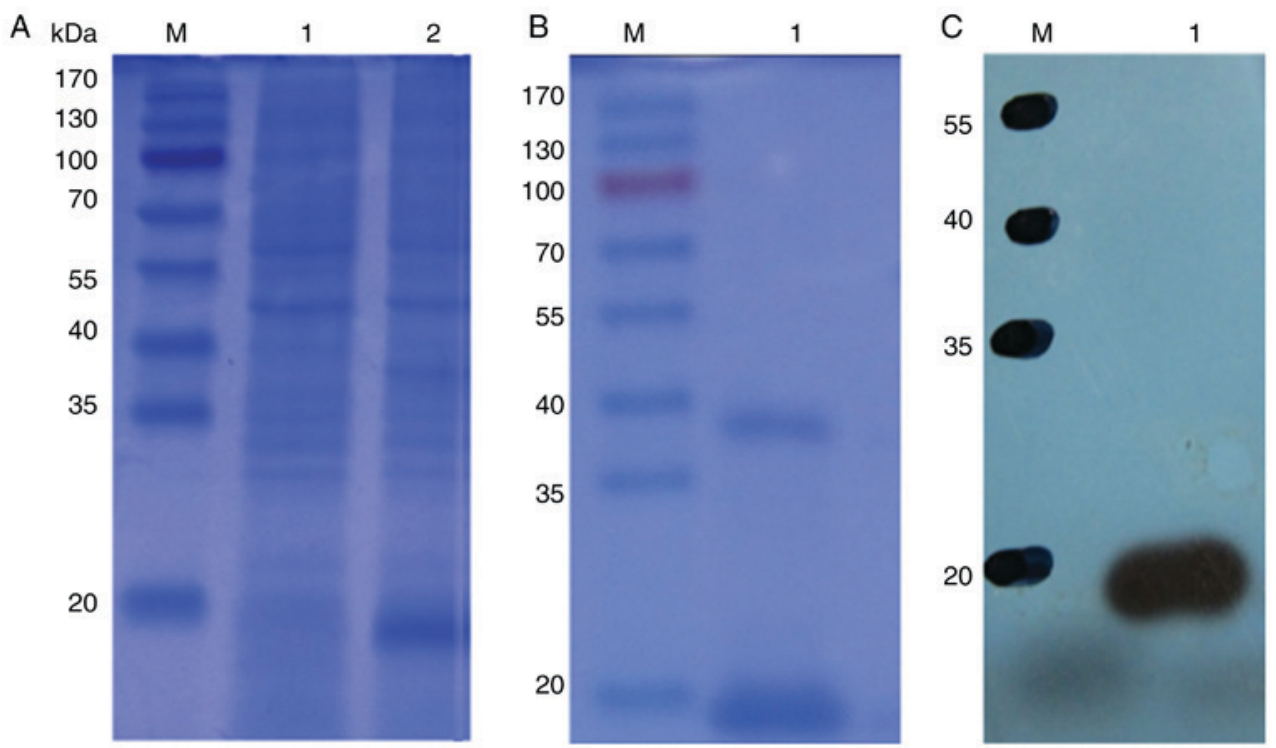

Figure 3. Expression, purification and identification of recombinant GPC3 protein. (A) Induction expression of recombinant GPC3 protein by SDS-PAGE analysis. Lane M, protein molecular weight marker; Lane 1, non-induction of GPC3; lane 2, induction of GPC3. (B) SDS-PAGE analysis of purification of recombinant GPC3 protein. M, standard protein molecular weight; lane 1, purified protein. (C) Confirmation of the recombinant protein by western blot analysis. The primary antibody was rabbit anti-His-tag monoclonal antibody. M, standard protein molecular weight; lane 1, purified protein. GPC3, glypican-3.

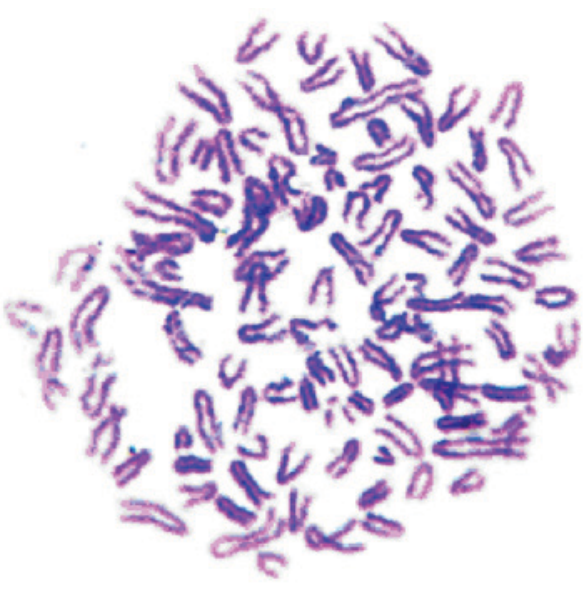

Figure 4. Chromosome map of mAb 2F3. The chromosome number of $\mathrm{mAb} 2 \mathrm{~F} 3$ was counted following staining with colcemid; representative image (original magnification, x100). mAb, monoclonal antibody.

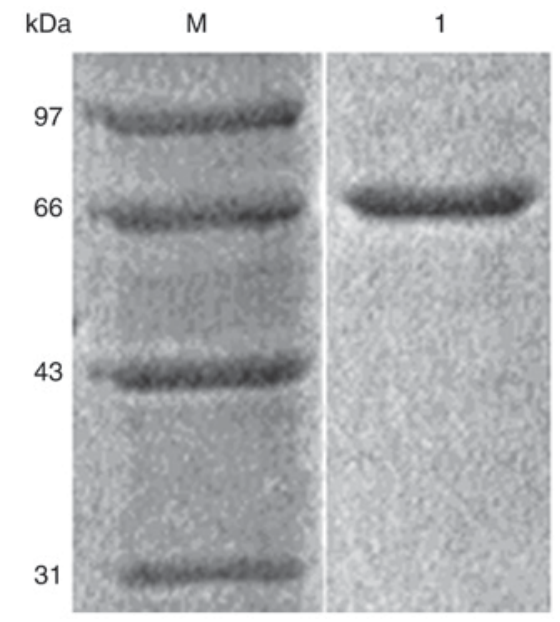

Figure 5. Western blot analysis with the purified monoclonal antibody $2 \mathrm{~F} 3$ Lane M, protein molecular weight marker; lane 1, total extracts of HepG2 cells.

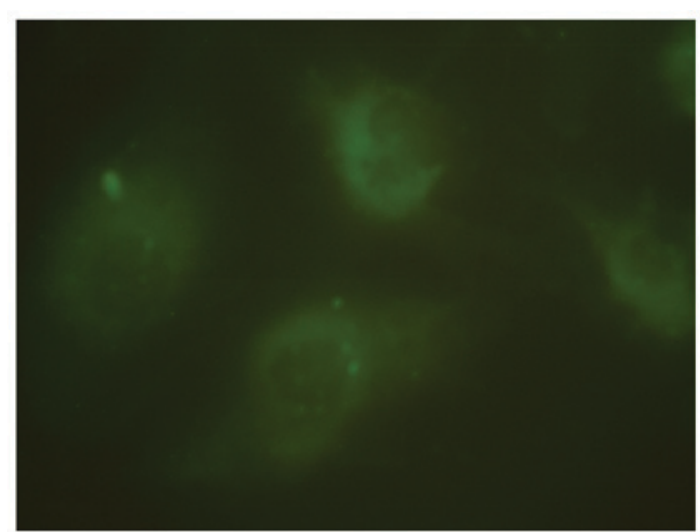

Figure 6. Immunofluorescence analysis of monoclonal antibody binding to native glypican-3 protein expressed in HepG2 cells (original magnification, $\mathrm{x} 400$ ).

optimization within E. coli and immunization via intrasplenic embedding. The results of the present study indicated that the specific $\mathrm{mAb}$ could be isolated by mouse hybridoma fusing and screening technology; the clone was denoted as 2F3 with the isotype of the generated $\mathrm{mAb}$ determined as $\mathrm{IgG} 1 / \kappa$. The $\mathrm{mAb}$ was present at a relatively high titer $\left(1: 10^{5}\right)$ in hybridoma supernatants and ascites as analyzed by indirect ELISA; its specificity was confirmed by western blot analysis, in agreement with previous reports that have demonstrated higher expression levels of GPC3 in HepG2 cells (34). Immunofluorescence experiments revealed strong signal intensity following interactions between $2 \mathrm{~F} 3$ and GPC3 in HepG2 cells. Our results indicate that the bacterially expressed GPC3 protein is biologically active and that the $2 \mathrm{~F} 3$ clone could specifically recognize the native GPC3 expressed in hepatoma cells.

A limitation of the present study is that the potential of the novel anti-GPC3 mAb in clinical settings was not investigated; thus, this antibody was not compared with other available antibodies. The present study aimed to generate the prokaryotic 
expression of recombinant GPC3, and the preparation and characterization of its $\mathrm{mAb}$. This novel $\mathrm{mAb}$ for GPC3 may provide a basis for therapeutic developments and applications in the future. The efficiency of the novel antibody in the early diagnosis of liver cancer requires further investigation.

\section{Acknowledgements}

The authors would like to thank Dr Yanyan Zhang (Institut National de la Santé et de la Recherche Médicale, Unité Mixte de Recherche 1170, Villejuf, France) for helpful suggestions and for critically reading the manuscript.

\section{Funding}

The present study was supported by Tianjin Municipal Health Bureau Key Project of People's Republic of China (grant no. 16KG105), National Natural Science Foundation of People's Republic of China (grant no. 81470982).

\section{Availability of data and materials}

The datasets used and/or analyzed during the current study are available from the corresponding author on reasonable request.

\section{Authors' contributions}

YW conceived and designed the present study. YZ, DQ, RL, YL, SS and YW collected, analyzed and interpreted the data. YL critically revised the manuscript for important intellectual content. YL and YW gave final approval for the version to be published. All authors read and approved the final manuscript, and agreed to be accountable for all aspects of the present study.

\section{Ethics approval and consent to participate}

The present study was approved by the Institutional Animal Care and Use Committee of Tianjin First Central Hospital (Tianjin, China) and conformed to the Guide for the Use and Care of Animals published by the National Institutes of Health (NIH Publication number 85-23, revised 1996) (11).

\section{Patient consent for publication}

Not applicable.

\section{Competing interests}

The authors declare that they have no competing interests.

\section{References}

1. Bosetti C, Turati F and La Vecchia C: Hepatocellular carcinoma epidemiology. Best Pract Res Clin Gastroenterol 28: 753-770, 2014.

2. Margini C and Dufour JF: The story of HCC in NAFLD: From epidemiology, across pathogenesis, to prevention and treatment. Liver Int 36: 317-324, 2016.

3. Xie DY, Ren ZG, Zhou J, Fan J and Gao Q: Critical appraisal of Chinese 2017 guideline on the management of hepatocellular carcinoma. Hepatobiliary Surg Nutr 6: 387-396, 2017.

4. Li C, Li R and Zhang W: Progress in non-invasive detection of liver fibrosis. Cancer Biol Med 15: 124-136, 2018.
5. Haruyama Y and Kataoka H: Glypican-3 is a prognostic factor and an immunotherapeutic target in hepatocellular carcinoma. World J Gastroenterol 22: 275-283, 2016.

6. Fleming $\mathrm{BD}$ and Ho M: Glypican-3 targeting immunotoxins for the treatment of liver cancer. Toxins (Basel) 8: E274, 2016.

7. Capurro M, Martin T, Shi W and Filmus J: Glypican-3 binds to Frizzled and plays a direct role in the stimulation of canonical Wnt signaling. J Cell Sci 127: 1565-1575, 2014.

8. Hippo Y, Watanabe K, Watanabe A, Midorikawa Y, Yamamoto S, Ihara S, Tokita S, Iwanari H, Ito Y, Nakano K, et al: Identification of soluble NH2-terminal fragment of glypican-3 as a serological marker for early-stage hepatocellular carcinoma. Cancer Res 64: 2418-2423, 2004

9. Wang L, Pan L, Yao M, Cai Y, Dong Z and Yao D: Expression of oncofetal antigen glypican-3 associates significantly with poor prognosis in HBV-related hepatocellular carcinoma. Oncotarget 7: 42150-42158, 2016.

10. Kaseb AO, Hassan M, Lacin S, Abdel-Wahab R, Amin HM, Shalaby A, Wolff RA, Yao J, Rashid A, Vennapusa B, et al: Evaluating clinical and prognostic implications of Glypican-3 in hepatocellular carcinoma. Oncotarget 7: 69916-69926, 2016.

11. Clark JD, Gebhart GF, Gonder JC, Keeling ME and Kohn DF: Special Report: The 1996 guide for the care and use of laboratory animals. ILAR J 38: 41-48, 1997.

12. Sharma D, Subbarao G and Saxena R: Hepatoblastoma. Semin Diagn Pathol 34: 192-200, 2017.

13. Shimizu H, Nakagawa M, Todaka N, Imaizumi K, Kurosawa Y, Maruyama T, Okumura CJ, Shibata T, Tanaka Y, Sato Y, et al: Improving the quality of a recombinant rabbit monoclonal antibody against PLXDC2 by optimizing transient expression conditions and purification method. Protein Expr Purif 146: 27-33, 2018.

14. Ni WW, Huang W, Wu DQ, Zhou YJ, Ji CM, Cao MD, Guo M, Sun JL and Wei JF: Expression and purification of a major allergen, Pla a 1, from Platanus acerifolia pollen and the preparation of its monoclonal antibody. Mol Med Rep 16: 2887-2892, 2017.

15. Shi J, Zhang DL, Cui ZC and Wang HM: Preparation and application of a novel monoclonal antibody specific for human B7-H3. Mol Med Rep 14: 943-948, 2016.

16. Simons A, Shaffer LG and Hastings RJ: Cytogenetic nomenclature: Changes in the ISCN 2013 compared to the 2009 edition. Cytogenet Genome Res 141: 1-6, 2013.

17. Turkes F and Chau I: Ramucirumab and its use in the treatment of hepatocellular carcinoma. Future Oncol, 2019 (Epub ahead of print).

18. Capurro M, Wanless IR, Sherman M, Deboer G, Shi W, Miyoshi E and Filmus J: Glypican-3: A novel serum and histochemical marker for hepatocellular carcinoma. Gastroenterology 125: 89-97, 2003.

19. Midorikawa $Y$, Ishikawa $S$, Iwanari $H$, Imamura $T$, Sakamoto $H$, Miyazono K, Kodama T, Makuuchi M and Aburatani H: Glypican-3, overexpressed in hepatocellular carcinoma, modulates FGF2 and BMP-7 signaling. Int J Cancer 103: 455-465, 2003.

20. Yamauchi N, Watanabe A, Hishinuma M, Ohashi K, Midorikawa Y, Morishita Y, Niki T, Shibahara J, Mori M, Makuuchi M, et al: The glypican 3 oncofetal protein is a promising diagnostic marker for hepatocellular carcinoma. Mod Pathol 18: 1591-1598, 2005.

21. Filmus J, Church JG and Buick RN: Isolation of a cDNA corresponding to a developmentally regulated transcript in rat intestine. Mol Cell Biol 8: 4243-4249, 1988.

22. Li M, Choo B, Wong ZM, Filmus J and Buick RN: Expression of OCI-5/glypican 3 during intestinal morphogenesis: Regulation by cell shape in intestinal epithelial cells. Exp Cell Res 235: 3-12, 1997.

23. Yoshikawa T, Nakatsugawa M, Suzuki S, Shirakawa H, Nobuoka D, Sakemura N, Motomura Y, Tanaka Y, Hayashi S and Nakatsura T: HLA-A2-restricted glypican-3 peptide-specific CTL clones induced by peptide vaccine show high avidity and antigen-specific killing activity against tumor cells. Cancer Sci 102: 918-925, 2011.

24. Attallah AM, El-Far M, Omran MM, Abdelrazek MA, Attallah AA, Saeed AM and Farid K: GPC-HCC model: A combination of glybican-3 with other routine parameters improves the diagnostic efficacy in hepatocellular carcinoma. Tumour Biol 37: 12571-12577, 2016. 
25. Ishiguro T, Sugimoto M, Kinoshita Y, Miyazaki Y, Nakano K Tsunoda H, Sugo I, Ohizumi I, Aburatani H, Hamakubo T, et al: Anti-glypican 3 antibody as a potential antitumor agent for human liver cancer. Cancer Res 68: 9832-9838, 2008.

26. Nakano K, Orita T, Nezu J, Yoshino T, Ohizumi I, Sugimoto M, Furugaki K, Kinoshita Y, Ishiguro T, Hamakubo T, et al: Anti-glypican 3 antibodies cause ADCC against human hepatocellular carcinoma cells. Biochem Biophys Res Commun 378 279-284, 2009

27. Zhang YF and Ho M: Humanization of high-affinity antibodies targeting glypican-3 in hepatocellular carcinoma. Sci Rep 6: $33878,2016$.

28. Nakano K, Ishiguro T, Konishi H, Tanaka M, Sugimoto M, Sugo I, Igawa T, Tsunoda H, Kinoshita Y, Habu K, et al: Generation of a humanized anti-glypican 3 antibody by CDR grafting and stability optimization. Anticancer Drugs 21: 907-916, 2010.

29. Ishiguro T, Kinoshita Y and Sugimoto M: Anti-glypican3 antibody for treatment of human liver cancer. Proceedings of the 101st annual meeting of the AACR. April 17-21. Abstract \#A2426. Washington, DC, 2010.

30. Ikeda M, Ohkawa S, Okusaka T, Mitsunaga S, Kobayashi S, Morizane C, Suzuki I, Yamamoto S and Furuse J: Japanese phase I study of GC33, a humanized antibody against glypican-3 for advanced hepatocellular carcinoma. Cancer Sci 105: 455-462, 2014.
31. Abou-Alfa GK, Puig O, Daniele B, Kudo M, Merle P, Park JW, Ross P, Peron JM, Ebert O, Chan S, et al: Randomized phase II placebo controlled study of codrituzumab in previously treated patients with advanced hepatocellular carcinoma. J Hepatol 65: 289-295, 2016.

32. Yin J, Li G, Ren X and Herrler G: Select what you need: A comparative evaluation of the advantages and limitations of frequently used expression systems for foreign genes. J Biotechnol 127: 335-347, 2007.

33. Köhler G and Milstein C: Continuous cultures of fused cells secreting antibody of predefined specificity. Nature 256: 495-497, 1975.

34. Wang YL, Wang YL, Mu H, Liu T, Chen XB and Shen ZY: Enhanced specific cytotoxicity of DCs transfected with GPC3 gene co-cultured with CIKs to GPC3-expressing hepatocellular carcinoma cells. Mol Med Rep 11: 3361-3367, 2015. 